\title{
Pediatric patients tolerance: a comparative study about using of Er:YAG laser and self-adhesive flowable composite for treatment of primary decayed teeth
}

\author{
Iole Vozza, DDS, PhD \\ Daniela Mari, DDS \\ Edoardo Pacifici, DDS, PhD \\ Valeria Luzzi, DDS, PhD \\ Gaetano lerardo, DDS, PhD \\ Gian Luca Sfasciotti, MD, DDS \\ Antonella Polimeni, MD, DDS
}

Pediatric Dentistry Division, Department of Oral and Maxillo-Facial Sciences, "Sapienza" University of Rome, Rome, Italy

\section{Corresponding author:}

lole Vozza

Pediatric Dentistry Division, Department of Oral and Maxillo-Facial Sciences, "Sapienza" University of Rome Via Caserta 6

00161 Rome

E-mail: iole.vozza@uniroma1.it

\section{Summary}

Aim. To verify the tolerance of children aged between $\mathbf{3}$ and $\mathbf{8}$ years, having class I caries and treated with Er:YAG laser in association with a new selfadhesive flowable resin in comparison with a highspeed diamond bur and a conventional flowable resin treatment.

Methods. A group of 80 healthy children (43 males and 37 females) ranging in age from 3 to 8 years, who had been diagnosed with at least one active occlusal non-cavitated superficial carious lesions in first or second deciduous molars, were selected for the present study. They were divided in $\mathbf{4}$ groups: group A: Class I occlusal cavities prepared using an Er:YAG laser and a self-adhesive flowable resin; Group B: Class I occlusal cavities prepared using an Er:YAG laser and a conventional flowable resin; Group C: Class I occlusal cavities prepared using a high-speed diamond bur and a self-adhesive flowable resin; Group D: Class I occlusal cavities prepared using a high-speed diamond bur and a conventional flowable resin. Before and after the treatments the patient tolerance was tested with the modified Wong-Baker pain level scale.

Results. In the first group, the tolerance rate was 95\% with 0 score (no hurt) for 19 patients; in Group $\mathrm{D}$, the tolerance rate was $75 \%$. Just one child of group D experienced hurting worst because of non cooperative patient.
Conclusion. From these results it emerged that, although the limits of the study, Er:Yag laser in association with self-adhering composite, is very effective in pediatric dentistry and is a good treatment option especially for non cooperative patients.

Key words: Er:YAG laser, occlusal cavities, selfadhesive flowable resin, pediatric tolerance, pediatric dentistry.

\section{Introduction}

Minimal invasive dentistry has been promoted with the development of new adhesive materials so to preserve healthy tooth tissue. It has allowed to complete smaller preparations by minimizing the requirement for retention and resistance form (1). Therefore, alternative methods, such as lasers, have been suggested for caries cavity preparation. Lasers have been used in dentistry for more than 20 years (2). Erbium: Yttrium- Aluminum Garnet (Erbium:YAG) lasers offers an alternative to conventional bur preparation with minimal tissue loss thanking to its $0.8 \mathrm{~mm}$ spot beam $(3,4)$. Erbium:Yag lasers emits energy in the wavelength of $2.94 \mu \mathrm{m}$ and is well absorbed by all biological tissues, including enamel and dentin (5). Once light from the laser is absorbed, it is converted to heat. The overheated water vaporizes and causes micro-explosions of tooth fragments without the risk of micro- and macrofractures, which have been observed when conventional rotating instruments are used (6). So it is very effective for enamel and dentin etching, caries removal and cavity preparation of primary and permanent teeth (3, 7-9). It determines a reduction of patient discomfort according to the absence of contact between rotary instruments and tooth that allows an atraumatic treatment without noise, pressure and vibration (6). Then reduced need for local anesthesia takes advantage for collaboration and tolerance of patients, above all for pediatric patients (10). It has been found that laser irradiated surfaces show a rough, clean surface without smear layer covering bur prepared cavities. This could be more favorable for the adhesion of restorative materials (10-11). Actually flowable resin composites are the most used materials due to their fluid injectability and non-stickiness characteristics (12). Recently, new self-adhering flowable resins have been developed. They have shown greater usefulness in uncooperative patients. Yazici et al. have also found in vitro that laser treatment increased the dentin bonding values of the self-adhesive flowable resin (13). The aim of 
this study was to verify the tolerance of children aged between 3 and 8 years, having class I caries and treated with Er:YAG laser in association with a new self-adhesive flowable resin in comparison with a high-speed diamond bur and a conventional flowable resin treatment.

\section{Materials and methods}

\section{Selection Criteria}

A group of 80 healthy children (43 males and 37 females) ranging in age from 3 to 8 years, who had been diagnosed with at least one active occlusal non-cavitated superficial carious lesions in first or second deciduous molars, were selected for the present study. Exclusion criteria were the presence of frank occlusal cavitation, poor oral hygiene, serious systemic diseases and bruxism. A written informed consent was obtained from all parents of little patients. The research was conducted in full accordance with the World Medical Association Declaration of Helsinki and the research protocol and consent form for the current study were reviewed and approved by the Medical Ethics Committee of "Sapienza" University of Rome. Caries lesions in the selected sites were assessed by visual inspection performed with patients positioned in a dental chair with reflector light, air/water spray and a plane buccal mirror using the visual-ranked method developed by Ekstrand et al. (14) under standardized conditions. The patients enrolled were divided randomly into 4 groups of 20 children each:

Group A: Class I occlusal cavities were prepared using an Er:YAG laser (Fidelis Plus II, Emmeciquattro Fotona, Italy) with wavelength 2,940 nm, $200 \mathrm{~mJ}$ energy and $15 \mathrm{~Hz}$ and a self-adhesive flowable resin (Vertise Flow, Kerr Corp, Orange CA, USA).

Group B: Class I occlusal cavities were prepared using an Er:YAG laser (Fidelis Plus II, Emmeciquattro Fotona, Italy) with wavelength 2,940 nm, $200 \mathrm{~mJ}$ energy and $15 \mathrm{~Hz}$ and a conventional flowable resin (Premise Flow, Kerr Corp).

Group C: Class I occlusal cavities were prepared using a high-speed diamond bur (835/010-4ML, Diatech Dental AG, Heerbrugg, Switzerland) under constant water cooling and a self-adhesive flowable resin (Vertise Flow, Kerr Corp, Orange CA, USA).

Group D: Class I occlusal cavities were prepared using a high-speed diamond bur (835/010-4ML, Diatech Dental AG, Heerbrugg, Switzerland) under constant water cooling and a conventional flowable resin (Premise Flow, Kerr Corp).

Visual and tactile feedback from an explorer was used to determine the end of caries removal. No additional "extension for prevention" and no visible preparation of undercuts were performed after the lesions were completely excavated. The etching was performed for 15 seconds with a $37.5 \%$ phosphoric acid etchant (Gel Etchant, Kerr, Orange, CA, USA), then rinsed for 15 seconds with an air-water spray and dried for 5 seconds, leaving the dentin slightly moist. All the flowable resin composites were applied according to the manufacturer's recommendations. For the conventional flowable resin the adhesive used (Optibond Solo Plus, Kerr, Orange, CA, USA) was applied onto the dentin surface according to the manufacturer's instructions (Figs. 1, 2). All the procedures were performed without local anesthesia. All the restorations were done by the same operator (DM) with cotton roll isolation and a chairside assistant. Of the 40 laser-prepared restorations, 29 were placed in lower molars and 11 in upper molars. In bur-prepared cavities, 24 restorations were placed in lower molars and 16 in upper molars. Before and after the treatments the patient tolerance was tested with the modified Wong-Baker pain level scale (15) (Fig. 3). A descriptive statistics was used to evaluate the results.

\section{Results}

The results of the present study are summarized in Table 1.

Just one child of Group D experienced hurting worst because of non cooperative patient. In the first group, where Class I occlusal cavities were prepared using an Er:YAG laser and a self-adhesive flowable resin, the tolerance rate was $95 \%$ with 0 score (no hurt) for 19 patients; in the second group, where Class I occlusal cavities were prepared using an Er:YAG laser and a conventional flowable resin the tolerance rate was $90 \%$; in the third group, where Class I occlusal cavities were prepared using a high-speed diamond bur and a self-adhesive flowable resin, the tolerance rate was $80 \%$; in the last group, where Class I occlusal cavities were prepared using a high-speed diamond bur and a conventional flowable resin, the tolerance rate was $75 \%$.

\section{Discussion and conclusion}

Anxiety in dentistry is frequent and includes both children and adults. It has been found that most of dental fears origin probably from mismanagement by the dentists during childhood (16). Nature of pain is variable and depends on objective and subjective factors (17). Until children reach school age, they cannot differentiate between pain and anxiety so it's very important to manage pain and fear successfully (18). The use of laser can be an efficient strategic therapy in pediatric dentistry due to minimal invasion (19) although no statistical differences were reported by different Authors between Er:YAG laser and air-rotor method in the effectiveness of caries removal (20, 21). The development of flowable composites improved the management of uncooperative patients. Some Authors (22) proposed a self-adhesive flowable resin for the restoration of small class I cavities, class $\mathrm{V}$ cavities, non-carious cervical lesions, and for a lin- 
GROUP A

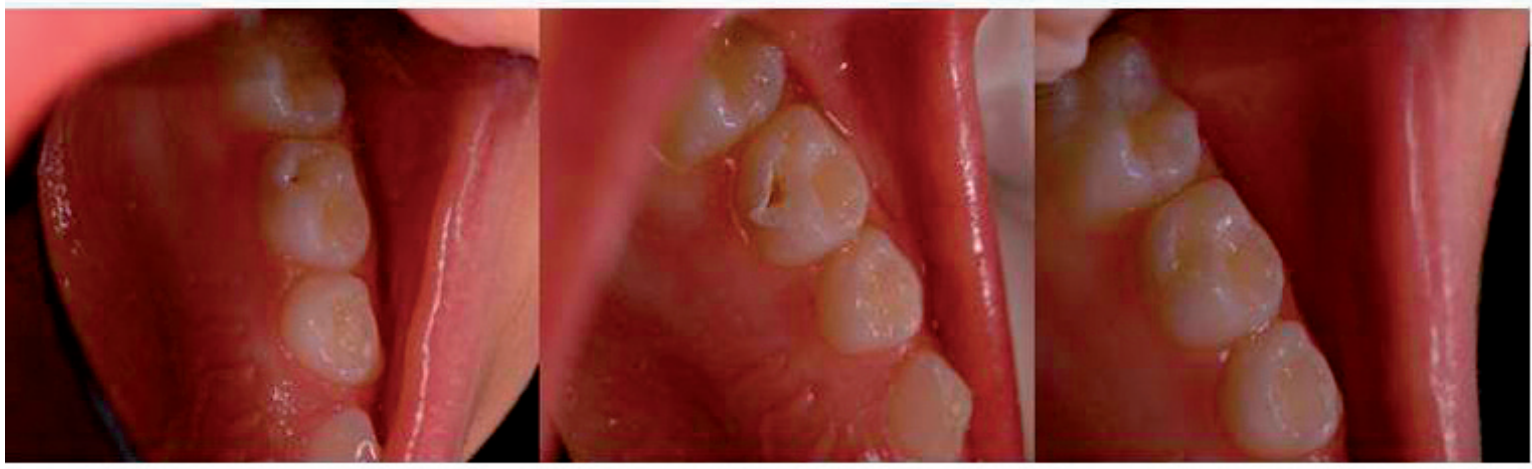

GROUP C

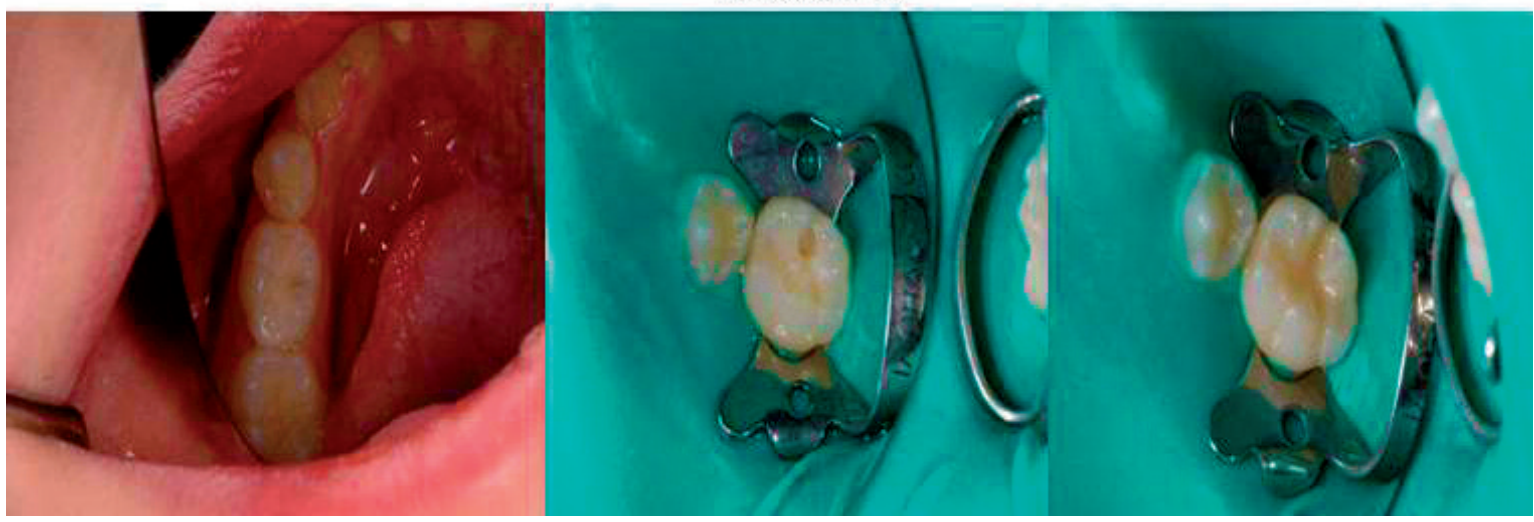

Figure 1. Case report of Group A and C.

GROUP B

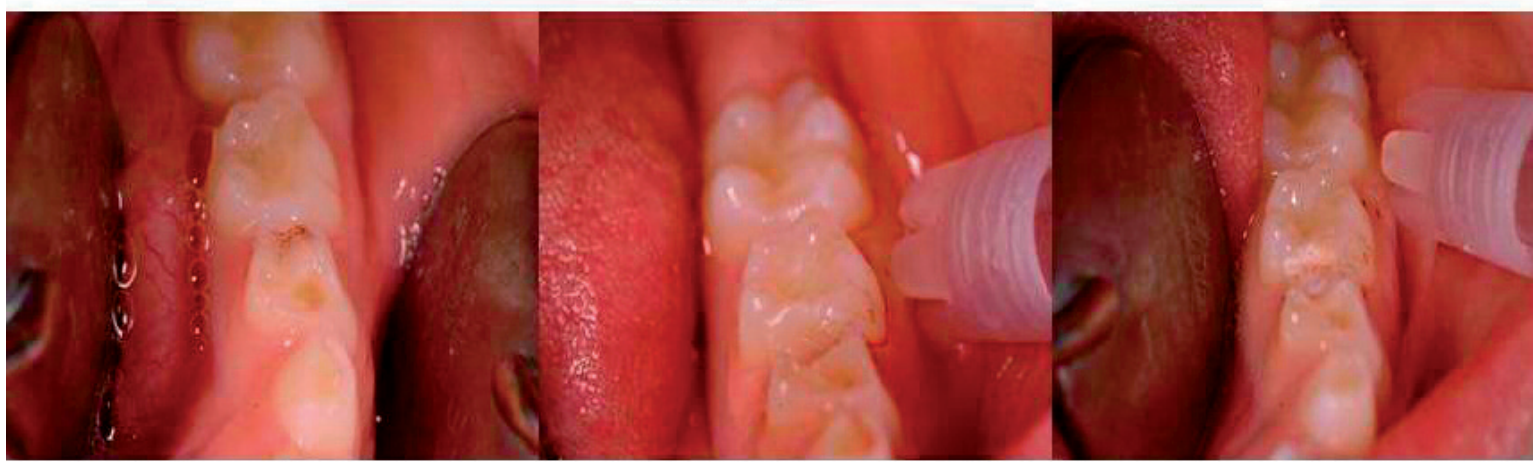

GROUP D

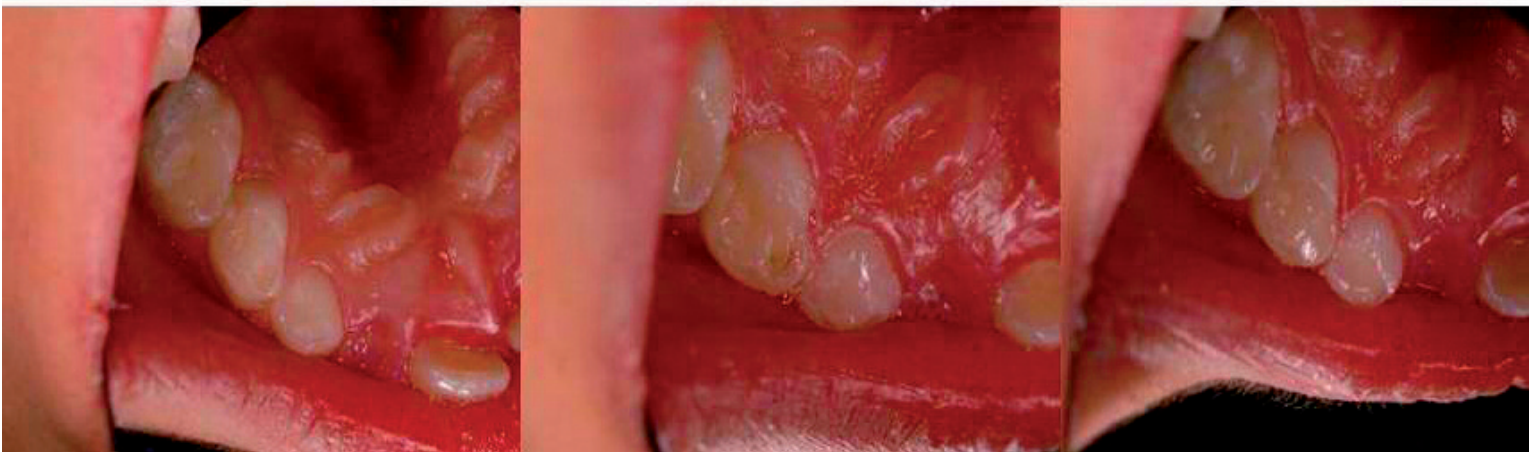

Figure 2. Case report of Group B and D. 
Pediatric patients tolerance: a comparative study about using of Er:YAG laser and self-adhesive flowable composite for treatment of primary decayed teeth

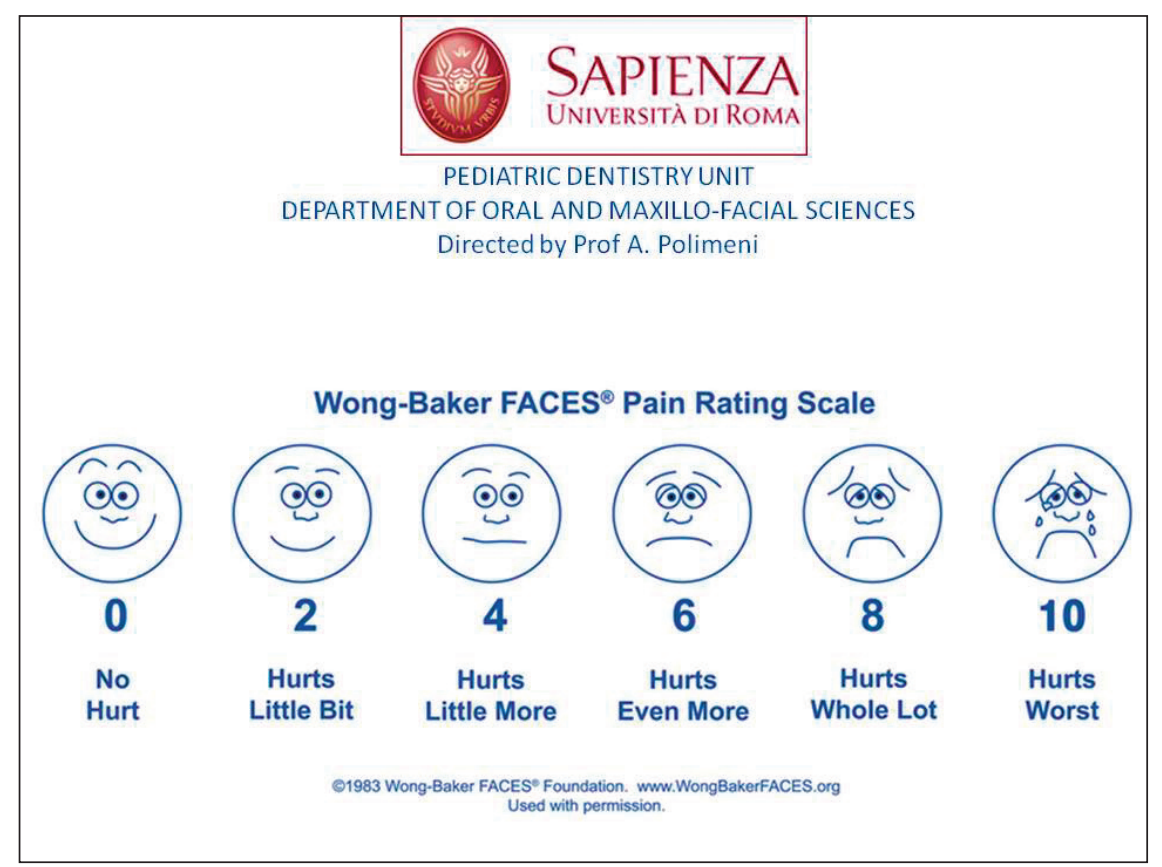

Figure 3. Wong-Baker scale.

Table 1. Results of technique acceptance from different groups of patients using Wong-Baker scale.

\begin{tabular}{lllllll}
\hline & $\mathbf{0}$ (no hurt) & $\begin{array}{l}\mathbf{2} \text { (hurts } \\
\text { little bit) }\end{array}$ & $\begin{array}{l}\mathbf{4} \text { (hurts } \\
\text { little more) }\end{array}$ & $\begin{array}{l}\mathbf{6} \text { (hurts } \\
\text { even more) }\end{array}$ & $\begin{array}{l}\mathbf{8} \text { (hurts } \\
\text { whole lot) }\end{array}$ & $\begin{array}{l}\mathbf{1 0} \text { (hurts } \\
\text { worst) }\end{array}$ \\
\hline GROUP A & 19 & & & 1 & & \\
GROUP B & 17 & 1 & 2 & & 1 & 1 \\
GROUP C & 14 & 2 & 3 & 1 & 2 & \\
GROUP D & 13 & 2 & 1 & & & \\
\hline
\end{tabular}

ing in class I and class II restorations, pit and fissure sealings, and porcelain repairs (23). Salerno et al. showed remarkably strong elastic capacities of a selfadhesive flowable resin (22). Pacifici et al. (24) found as this new self-adhering flowable resin composite established on primary dentin bond strengths values similar to those of glass ionomer cements routinely used for restorations of primary teeth. From these results it emerged that, although the limits of the study, Er:Yag laser, in association with self-adhering composite, is very effective in pediatric dentistry and is a good treatment option especially for non cooperative patients.

\section{References}

1. Murdoch-Kinch CA, McLean ME. Minimal invasive dentistry. Journal of the American Dental Association. 2003;134(1):8795.

2. Yazici AR, Baseren M, Gorucu J. Clinical comparison of burand laser-prepared minimally invasive occlusal resin composite restorations: two-year follow-up. Oper Dent. 2010 SepOct;35(5):500-7.
3. Kornblit R, Trapani D, Bossù M, Muller-Bolla M, Rocca JP, Polimeni A. The use of Erbium: YAG laser for caries removal in paediatric patients following minimally invasive dentistry concepts. European Journal of Paediatric Dentistry. 2008;9 (2):81-87.

4. Eberhard J, Bode K, Hedderich J, Jepsen S. Cavity size difference after caries removal by a fluorescence-con- trolled Er:YAG laser and by conventional bur treatment. Clinical Oral Investigations. 2008;12(4):311-318.

5. Matsumoto K, Hossain M, Hossain MM, Kawano H, Kimura Y. Clinical assessment of Er, Cr: YSGG laser application for cavity preparation. Journal of Clinic Laser Medicine and Surgery. 2002;20(1):17-21.

6. Fornaini C, Riceputi D, Lupi-Pegurier L, Rocca JP. Patient responses to Er:YAG laser when used for conservative dentistry. Lasers Med Sci. 2012 Nov;27(6):1143-9.

7. Hossain JM, Nakamura Y, Yamada Y, Murakami Y, Matsumoto $\mathrm{K}$. Compositional and structural changes of human dentin following caries removal by Er, Cr: YSGG laser irradiation in primary teeth. Journal of Clinical Pediatric Dentistry. 2002;26(4):377-382.

8. Cehreli SB, Gungor HC, Karabulut E. Er,Cr:YSGG laser pretreatment of primary teeth for bonded fissure sealant application: a quantitative microleakage study. Journal of Adhesive Dentistry. 2006;8(6):381-386. 
9. Parkins F. Lasers in pediatric and adolescent dentistry. Dental Clinics of North America. 2000;44(4):821-830.

10. Aranha AC, De Paula Eduardo C, Gutknecht N, Marques MM, Ramalho KM, Apel C. Analysis of the interfacial micromorphology of adhesive systems in cavities prepared with $\mathrm{Er}$, Cr: YSGG, Er:YAG laser and bur Microscopy Research and Technique. 2007;70(8):745-751.

11. Delmé KI, De Moor RJ. Scanning electron microscopic evaluation of enamel and dentin surfaces after Er: YAG laser preparation and laser conditioning. Photomedicine and Laser Surgery. 2007;25(5):393-401.

12. Bayne SC, Thompson JY, Swift EJ Jr, Stamatiades P, Wilkerson M. A characterization of first-generation flowable composites. J Am Dent Assoc. 1998;129(5):567-577.

13. Yazici AR, Agarwal I, Campillo-Funollet M, Munoz-Viveros C, Antonson SA, Antonson DE, Mang T. Effect of laser preparation on bond strength of a self-adhesive flowable resin. Lasers Med Sci. 2013 Jan;28(1):343-7.

14. Ekstrand KR, Ricketts DN, Kidd EA. Reproducibility and accuracy of three methods for assessment of demineralization depth of the occlusal surface: an in vitro examination. Caries Research. 1997;31(3):224-231.

15. Wong DL, Baker CM. Pain in children: comparison of assessment scales. Pediatr Nurs. 1988 Jan-Feb;14(1):9-17.

16. Ayer WA Jr, Domoto PK, Gale EN, Joy ED Jr, Melamed BG. Overcoming dental fear: strategies for its prevention and management. J Am Dent Assoc. 1983 Jul;107(1):18-27.

17. Genovese MD, Olivi G. Laser in paediatric dentistry: patient acceptance of hard and soft tissue therapy. Eur J Paediatr Dent. 2008 Mar;9(1):13-7.

18. Zurfluh MA, Daubländer M, van Waes HJ. Comparison of two epinephrine concentrations in an articaine solution for local anesthesia in children. Swiss Dent J. 2015;125(6):698-709.

19. Nazemisalman B, Farsadeghi M, Sokhansanj M. Types of Lasers and Their Applications in Pediatric Dentistry. J Lasers Med Sci. 2015;6(3):96-101.

20. Shigetani Y, Tate Y, Okamoto A, Iwaku M, Abu-Bakr N. A study of cavity preparation by Er:YAG laser. Effects on the marginal leakage of composite resin restoration. Dent Mater J. 2002 Sep;21(3):238-49.

21. Bohari MR, Chunawalla YK, Ahmed BM. Clinical evaluation of caries removal in primary teeth using conventional, chemomechanical and laser technique: an in vivo study. J Contemp Dent Pract. 2012 Jan 1;13(1):40-7.

22. Salerno M, Derchi G, Thorat S, Ceseracciu L, Ruffilli R, Barone AC. Surface morphology and mechanical properties of new-generation flowable resin composites for dental restoration. Dent Mater. 2011 Dec;27(12):1221-8.

23. Goracci C, Margvelashvili M, Giovannetti A, Vichi A, Ferrari $M$. Shear bond strength of orthodontic brackets bonded with a new self-adhering flowable resin composite. Clin Oral Investig. 2013 Mar;17(2):609-17.

24. Pacifici E, Chazine M, Vichi A, Grandini S, Goracci C, Ferrari M. Shear-bond strength of a new self-adhering flowable restorative material to dentin of primary molars. J Clin Pediatr Dent. 2013 Winter;38(2):149-54. 
Reproduced with permission of the copyright owner. Further reproduction prohibited without permission. 